\title{
Correction to: Music, Mind, and Embodiment
}

Richard Kronland-Martinet, Mitsuko Aramaki, and Sølvi Ystad

\section{Correction to: \\ R. Kronland-Martinet et al. (Eds.): \\ Music, Mind, and Embodiment, LNCS 9617, https://doi.org/10.1007/978-3-319-46282-0}

In the original version of the book, the following belated corrections have been incorporated:

In the chapter "Musical Meter, Rhythm and the Moving Body: Designing Methods for the Analysis of Unconstrained Body Movements", the acknowledgment was missing. This has been added.

In the chapter "Cross-Cultural Comparisons of Unconstrained Body Responses to Argentinian and Afro-Brazilian Music", the acknowledgment has been updated.

The correction book has been now updated with the changes.

The updated versions of the chapters can be found at https://doi.org/10.1007/978-3-319-46282-0_3

https://doi.org/10.1007/978-3-319-46282-0_30

(C) Springer International Publishing Switzerland 2018

R. Kronland-Martinet et al. (Eds.): CMMR 2015, LNCS 9617, p. E1, 2016.

https://doi.org/10.1007/978-3-319-46282-0_31 